\title{
Insurance coverage of medical foods for treatment of inherited metabolic disorders
}

\author{
Susan A. Berry, MD¹, Mary Kay Kenney, PhD², Katharine B. Harris, MBA ${ }^{3}$, Rani H. Singh, PhD, RD4, \\ Cynthia A. Cameron, PhD ${ }^{5}$, Jennifer N. Kraszewski, $\mathrm{MPH}^{6}$, Jill Levy-Fisch, BA ${ }^{7}$, Jill F. Shuger, $\mathrm{ScM}^{8}$, \\ Carol L. Greene, MD', Michele A. Lloyd-Puryear, MD, PhD ${ }^{10}$ and Coleen A. Boyle, PhD, MS ${ }^{11}$
}

\begin{abstract}
Purpose: Treatment of inherited metabolic disorders is accomplished by use of specialized diets employing medical foods and medically necessary supplements. Families seeking insurance coverage for these products express concern that coverage is often limited; the extent of this challenge is not well defined.
\end{abstract}

Methods: To learn about limitations in insurance coverage, parents of 305 children with inherited metabolic disorders completed a paper survey providing information about their use of medical foods, modified low-protein foods, prescribed dietary supplements, and medical feeding equipment and supplies for treatment of their child's disorder as well as details about payment sources for these products.

Results: Although nearly all children with inherited metabolic disorders had medical coverage of some type, families paid "out of pocket" for all types of products. Uncovered spending was reported for $11 \%$ of families purchasing medical foods, $26 \%$ purchasing supplements, $33 \%$ of those needing medical feeding supplies, and $59 \%$ of families requiring modified low-protein foods. Forty-two percent of families using modified low-protein foods and $21 \%$ of families using medical foods reported additional treatment-related expenses of $\$ 100$ or more per month for these products.

Conclusion: Costs of medical foods used to treat inherited metabolic disorders are not completely covered by insurance or other resources.

Genet Med advance online publication 18 April 2013

Key Words: diet therapy; inborn errors of metabolism; insurance coverage; neonatal screening

\section{INTRODUCTION}

Inherited metabolic disorders (IMDs) are a complex group of genetic conditions in which an enzyme deficiency prevents normal metabolism. When the enzyme deficiency prevents normal use of nutrients, effective treatment of the associated IMD depends primarily on dietary restriction because use of off-the-shelf foods containing substances that cannot be metabolized by the affected person results in toxic effects. Typically, a health-care provider prescribes a specialized diet restricting the food component that cannot be metabolized. For example, individuals affected with phenylketonuria are unable to properly metabolize the amino acid phenylalanine, which must be selectively limited in their diet to prevent severe intellectual disability. For some disorders, food products restricted in the offending material are available without modification of conventional products, e.g., galactosemia is treated in infancy by conventional formulas using sucrose as a sugar source rather than the galactose-containing disaccharide, lactose. For others, particularly disorders of amino acid metabolism, conventional products that restrict the offending amino acid(s) are not available. Treatment of disorders of amino acid metabolism requires products specially manufactured to exclude an offending amino acid or amino acids. These are typically supplied in powdered formula or in other product forms such as bars, capsules, or ready-to-consume liquids. Beyond powdered formulas, bars, and capsules, physicians can also prescribe modified low-protein foods: products specially manufactured to provide versions of common foods made with restricted protein content. Such preparations are referred to collectively as "medical foods," defined by the US Food and Drug Administration in section 5(b) of the Orphan Drug Act (21 U.S.C. 360ee (b) (3)) as "food which is formulated to be consumed or administered enterally under the supervision of a physician and which is intended for specific dietary management of the disease or condition for which distinctive nutritional requirements, based on recognized scientific principles, are established by medical evaluation."

In addition to medical foods (formulas, bars, and modified low-protein foods), other specialized nutritional products, including high doses of vitamins and amino acids, are used in

\footnotetext{
${ }^{1}$ Department of Pediatrics, University of Minnesota, Minneapolis, Minnesota, USA; ${ }^{2}$ Office of Epidemiology, Policy and Evaluation, Health Resources and Services Administration, Rockville, Maryland, USA; ${ }^{3}$ Wadsworth Center, New York State Department of Health, Albany, New York, USA; ${ }^{4}$ Department of Human Genetics, Emory University, Atlanta, Georgia, USA; ${ }^{5}$ Michigan Public Health Institute, Okemos, Michigan, USA; ${ }^{6}$ ational Center for Complementary and Alternative Medicine, National Institutes of Health, Bethesda, Maryland, USA; ${ }^{7}$ Save Babies Through Screening Foundation, Inc., Cincinnati, Ohio, USA; ${ }^{8}$ Maternal and Child Health Bureau, Health Resources and Services Administration, Rockville, Maryland, USA; ${ }^{9}$ Department of Pediatrics, University of Maryland School of Medicine, Baltimore, Maryland, USA; ${ }^{10}$ Eunice Kennedy Shriver National Institute of Child Health and Human Development, Bethesda, Maryland, USA; ${ }^{11}$ National Center on Birth Defects and Developmental Disabilities, Centers for Disease Control and Prevention, Atlanta, Georgia, USA. Correspondence: Susan A. Berry (berry002@umn.edu)
} 
the management of IMDs. The use of medical foods, modified low-protein foods, amino acid supplements, and high doses of vitamins for individuals with IMDs is not merely an optional, alternative food choice but rather a medical necessity. Although each metabolic disorder has its own pathological profile if left untreated, children who cannot consistently obtain specialized nutritional products may experience serious adverse health effects, including severe acidosis and/or coma requiring complex hospital care, intellectual impairment, behavioral dysfunction, inadequate growth, abnormal development, nutrient deficiencies, and even death.

The cost of these foods and products can be high. The prepared formulas that comprise the major part of the medical foods used for IMD treatment are more expensive than standard infant formulas. For example, a case of standard powdered infant formula costs the state of Mississippi Women, Infants and Children (WIC) program $\$ 17.66$, whereas a case of a specialized medical food formula for infants costs $\$ 202.32$. A case of formula designed for an older child costs $\$ 405.60 .{ }^{2}$ Modified low-protein foods are also much more expensive than corresponding nonmodified products. A box of low-protein chocolate cake mix costs $\$ 10$ as compared with $\$ 3.25$ for a generic store brand of cake mix. A box of low-protein pasta costs $\$ 9.25$, nearly four times the price of a regular store brand $(\$ 2.49){ }^{3}$ Overall, modified low-protein foods cost two to eight times more than their unmodified counterparts. ${ }^{4}$

Some states pay for and provide medical foods as a part of their overall newborn screening (NBS) program. Most states that do not directly provide medical foods have enacted legislation that requires insurers to provide coverage for medical foods ${ }^{5,6}$ However, policies regarding coverage vary from state to state; even when legislation has been enacted, there are exceptions and exclusions, such as the Employee Retirement Income Security Act exemptions to state legislative mandates. ${ }^{6}$ Because levels of insurance coverage for medical foods are not uniform across states, ${ }^{7}$ three of the Regional Genetic and Newborn Screening Service Collaboratives surveyed families with a child affected with an IMD requiring medical foods, modified low-protein foods, high doses of vitamins, and/or amino acid supplements. The purpose of the survey was to ascertain use of these products, sources and methods of payment, limitations in insurance coverage for purchase of the products, and the amount of "out-of-pocket" (OOP) expenditures required of the surveyed families to make these medically necessary purchases.

\section{Survey development}

\section{MATERIALS AND METHODS}

Working jointly, three Health Resources and Services Administration Maternal and Child Health Bureau Regional Genetic and Newborn Screening Services Collaboratives (http://www.nccrcg.org)—Region 2 New York-Mid-Atlantic Consortium for Genetic and Newborn Screening Services (includes Delaware, District of Columbia, Maryland, New Jersey, New York, Pennsylvania, Virginia, and West Virginia); Region 3 Southeast Newborn Screening and Genetics Collaborative (includes Alabama, Florida, Georgia, Louisiana, Mississippi, North Carolina, Puerto Rico, South Carolina, Tennessee, and the Virgin Islands); and Region 4 Genetics Collaborative (comprising Illinois, Indiana, Kentucky, Michigan, Minnesota, Ohio, and Wisconsin)-developed a survey instrument and conducted the survey. The survey was piloted in two centers in different regions and two family focus groups provided feedback regarding the instrument. Questions were refined on the basis of feedback from the focus groups and results of the survey pilot.

\section{Survey administration}

Materials for consent were prepared, and institutional review board approvals obtained for administration of a pen-andpaper survey based on a convenience sample of parents of children with an IMD. Recruitment methods varied by clinic site, but in general, all parents of children with conditions requiring the use of medical foods who had clinic appointments during the summer of 2009 were asked to participate. Parents of 305 children $<18$ years of age completed the anonymous survey during regular clinic visits. The survey was administered in 14 centers in the three participating regions. Twenty-two of the respondents lived in one of the nine states where medical foods are supplied as part of their state's NBS program (North Carolina). ${ }^{5}$ Medical diagnosis and medical food reference lists were included with the survey document as aids for parents in responding to survey questions.

\section{Data and survey analysis}

The final paper survey included questions about health insurance coverage for the child's health care (i.e., public or private insurance, WIC, military/veterans program, Indian Health Service, or other source); the medical foods, modified lowprotein foods (e.g., low-protein pastas, breads, and cereals), prescribed dietary supplements (i.e., amino acids, vitamins, carnitine, or other supplements), and medical feeding supplies/ equipment (e.g., pumps, port-o-caths, syringes, tubing, and Mic-key buttons) used by the child; an estimate of how much families had to pay OOP for their child's dietary treatment (asked by ranges: $\$ 0 /$ month, $>\$ 0-<\$ 100 /$ month, $\$ 100-<\$ 500 /$ month, $\$ 500-\$ 1,000 /$ month, and $>\$ 1,000 /$ month); the extent to which these items were covered by their health plan; and the annual "cap" or limit on the amount covered by the family's policy. Demographic information was limited to age, diagnosis, and state in which the child resided. Data on annual caps are not reported here due to the number of null responses.

The data were first analyzed using basic descriptive statistics such as frequencies and percentage statistics for the survey items described above. $\chi^{2}$ Tests were used to determine if there were statistically significant differences in the distribution of (i) reported payment sources used by parents purchasing medical foods, modified low-protein foods, dietary supplements, and medical feeding supplies and (ii) the level of OOP expenses families paid for the four different product types. The units of analysis for these tests were mentions 
of reported payment sources. Bonferonni-adjusted post hoc tests $(P=0.005)$ were performed following the finding of significant results for each $\chi^{2}$ test.

\section{RESULTS}

Of the 305 children of families that responded to the survey, 150 (49\%) were newborn to 5 years of age, 91 (30\%) were between 6 and 11 years, and $64(21 \%)$ were between 12 and 17 years. Fifty percent of the children had phenylketonuria, $10 \%$ had other amino acidemias, $12 \%$ had organic acidemias, $6 \%$ had urea-cycle disorders, $12 \%$ had fatty acid oxidation disorders, and $10 \%$ had other conditions or an unspecified diagnosis. The distribution of disorders reflects the general prevalence of the disorders within the US population and the nature of therapies for the conditions.

The survey asked families to describe all sources of insurance coverage (private, public, and none) for health care or payment through WIC for medical foods and formula available to them. In this sample, only three families specified that their children had no coverage for health care. A total of $25 \%$ of the children had multiple funding sources for their coverage. Medicaid (55\%, 167 families) and private insurance (52\%, 159 families) were common sources of partial or full coverage reported by families. WIC was the only other entity reported as a source of coverage by more than $10 \%$ (33) of families. Of the subset of 22 patients from a state where medical foods are provided by the NBS program, multiple sources were still employed, and only one family indicated they received their medical foods from the state program.

Families reported obtaining their dietary products, supplements, and supplies from a variety of sources, depending on the nature of the product being used. Families requiring medical

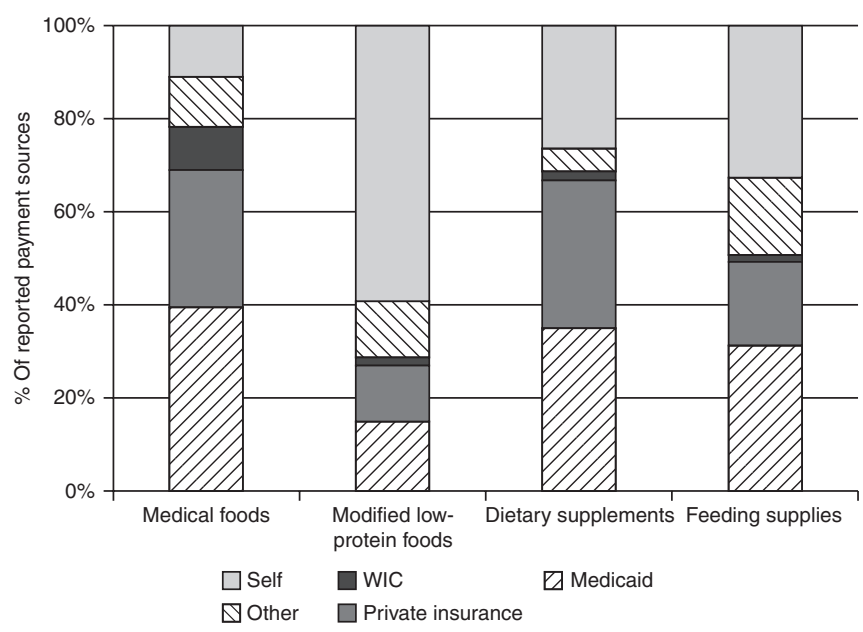

Figure 1 Percentage of reported payment sources used for medical foods and related products. Percentage of payment sources used for medical foods, dietary supplements, modified low-protein foods, and feeding supplies is noted on the $y$ axis. Families used more than one payment source for some products and often paid for multiple products. Other, military health benefits and miscellaneous other sources; Self, parents' out-of-pocket expenditures; WIC, Women, Infant, and Children programs. foods reported purchasing them primarily from pharmacies (34\%), hospital/clinics (18\%), health departments (14\%), and medical supply companies (12\%). More than two-thirds (69\%) of families requiring dietary supplements reported pharmacies as the source from which they obtained these products. By contrast, families requiring modified low-protein foods largely obtained them from Internet sources (41\%), health food stores (16\%), and directly from manufacturers (14\%). Among families purchasing feeding supplies, pharmacies (32\%), medical supply companies (17\%), and clinics (18\%) were the principal sources. For each product type, however, families often obtained the products from multiple sources.

Affected children often required items from multiple categories for nutritional support of their conditions: 257 families (84\%) reported using medical foods, 181 families (59\%) reported using modified low-protein foods, 152 families (50\%) reported using one or more dietary supplements, and 152 families (50\%) reported using feeding supplies. Overall, the parents surveyed indicated that $80 \%$ of children used at least two of the surveyed product types and $48 \%$ used three or more.

Families relied on multiple payment sources for individual products and/or may have used multiple payment sources for multiple product types. Figure 1 shows all reported payment sources by product type. $\chi^{2}$ Test results indicated that across the product types, there were significant differences in the distribution of reported payment sources used to purchase the different types of products $\left(\chi^{2}=(12, N=753) 159.53, P<0.005\right)$. Medicaid often covered medical foods, dietary supplements, and feeding (40,35, and $31 \%$ of reported sources, respectively). Private insurance also frequently contributed to the coverage of medical foods (30\%) and dietary supplements (32\%).

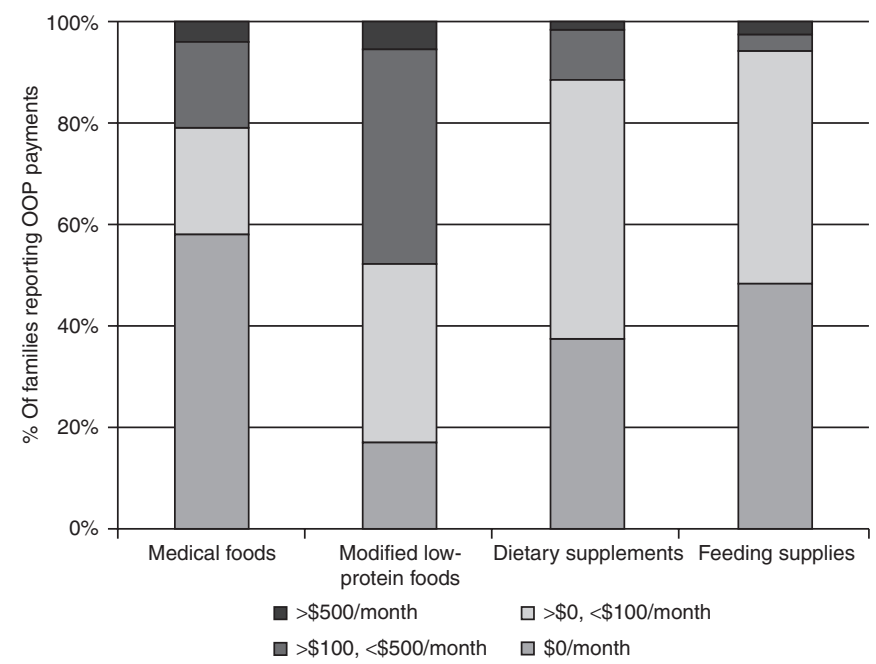

Figure 2 Cost per month paid OOP for medical foods and related products. Percentage of families reporting OOP expenditures for medical foods, dietary supplements, modified low-protein foods, and feeding supplies is noted on the $y$ axis. Families often paid for more than one product type. Families reported the range of costs they paid per month beyond insurance or other coverage for medical foods, modified low-protein foods, supplements, and supplies. Shown here are the ranges of OOP expenditures for each type of product (on the $x$ axis); OOP, out of pocket. 
Of note was the frequency of OOP expenses parents were required to pay for nutritional treatment of their affected child due to a lack of coverage from one of the other sources included in the survey (i.e., Medicaid, private insurance, WIC, or other source). Families paid OOP for all types of products, most notably for modified low-protein foods. OOP spending accounted for $11 \%$ of medical foods payment sources, $26 \%$ of supplement sources, $33 \%$ of feeding supplies payment sources, and $\sim 60 \%$ of payment sources for modified low-protein foods. Bonferroni-adjusted post hoc tests indicated that modified lowprotein foods were the only product type for which the percentage of total mentions of outside coverage was not more frequent than OOP purchasing (medical foods: $\chi^{2}(1, N=281)=170.08$, $P<0.005$; modified low-protein food: $\chi^{2}(1, N=174)=5.89, P>$ $0.005)$; dietary supplements: $\chi^{2}(1, N=160)=36.1, P<0.005$; and medical feeding supplies $\left.\chi^{2}(1, N=138)=16.4, P<0.005\right)$.

Figure 2 shows the percentage of parents reporting OOP expenditures by product type. $\chi^{2}$ Test results indicated that across product types there were statistically significant differences in the distribution of OOP expenditure levels for the different types of products $\left(\chi^{2}(9, N=632)=141.27, P<0.005\right)$. A total of $21 \%$ of parents purchasing medical foods paid more than $\$ 100$ per month (beyond the costs for an unaffected child), as did $48 \%$ of parents purchasing modified low-protein foods, $11 \%$ purchasing dietary supplements, and $6 \%$ requiring feeding supplies. Some families reported paying $\$ 500$ or more for medical foods (4\%), modified low-protein foods (5\%), dietary supplements (2\%), and feeding supplies (3\%). Bonferroni-adjusted post hoc tests indicated that modified low-protein foods were the only product type for which parents overall reported paying in excess of $\$ 100 /$ month more often than they paid $<\$ 100 /$ month (medical foods: $\chi^{2}(1, N=224)=59.93, P<0.005$; modified low-protein food: $\left.\chi^{2}(1, N=165)=0.30, P>0.005\right)$; dietary supplements: $\chi^{2}(1, N=123)=73.37, P<0.005$; and medical feeding supplies $\left.\chi^{2}(1, N=120)=93.6, P<0.005\right)$. Although the majority of parents purchased multiple product types to fully meet the medical needs of their children, we were not able to determine the additive OOP costs for those parents due to the categorical nature of the response options.

Overall, the survey results found that $41 \%$ of families had OOP expenses for some of the products that were purchased to maintain IMD treatment, with some families paying for the cost of multiple products. Medical foods were more frequently covered by insurance and obtained from medically based sources, whereas families more often paid OOP for modified low-protein foods and obtained these from the Internet or directly from the manufacturer.

\section{DISCUSSION}

This is the first survey to obtain specific information about insurance coverage available to families who must use medical foods and related products. The populations of the three regions in this collaboration represent $57 \%$ of the US population, based on US 2010 Census figures. Each state has a different regulatory environment for payment for these products, but when we summarized the data from these centers, our findings revealed, at best, uneven coverage for these needed treatments, with an associated potential for financial burdens for these families managing their child's chronic metabolic disorder.

We found that some families experienced additional expenditures to cover the costs of their child's required medical food treatment. Many had OOP expenses; a few families had expenses amounting to more than $\$ 500$ per month. Although 99\% percent of the children in our survey had some type of health-care coverage, the insurance often did not provide complete coverage for medical foods, modified low-protein foods, supplements, or feeding supplies necessary for management of an IMD.

Of note, the level of health insurance coverage observed in this study is not typical of the general population, for which $\sim 10 \%$ of children remain uncovered. ${ }^{8}$ Some of this discrepancy in coverage rates may have resulted from a selection bias from our convenience survey of individuals who already had access to health services due to their child's diagnosis. Consequently, we suggest that the families in this sample represent a best-case scenario relative to insurance coverage relative to medical foods.

Our study had specific limitations. The families as respondents had a great deal of difficulty identifying all of their OOP costs. Although this underscores the complexities in understanding insurance coverage for families even when they are frequent users of this service, it also limited our ability to gather detailed quantitative information about the magnitude of expenses related to the use of medical foods and associated products. Despite these shortcomings, our observations show that families had significant OOP expenses for treatments that are essential for these complex disorders.

We also found that families depended on need-based resources, such as Medicaid or WIC, for purchasing medical foods. In several states surveyed here, WIC was an important source of support for many families. WIC programs typically provide families with formulas, including medical foods for infants and very young children. When assessed by age group, WIC provided a notable portion of required nutritional treatments for infants and younger children. However, because such programs typically terminate coverage at age 5 , older children were unlikely to have access to this resource.

We did not extend our survey to include adults. As originally conceived, the study was undertaken with funding specific to assessment of children. However, in our observation, limitations on coverage for adults are substantially worse than those on coverage for children, particularly because resources such as WIC are not available to older children or adults. Insurance companies have also often terminated coverage for these specialized products at age 21. Medicare Part D, a common resource for adults, for example, excludes coverage of amino acid supplements. Because the care for these conditions does not end with childhood, these exceptions and terminations of coverage are particularly disturbing.

We asked families about the sources of their products with the expectation that if they needed to acquire products directly from the manufacturer or from Web-based sources on the 
Internet that they were likely purchasing their products directly and paying themselves. We surmised that products obtained from a pharmacy or directly from a department of health source were likely covered, with less financial impact on the family. The reported sources of products reflected these assumptions, with most medical foods, supplements, and supplies being obtained from medically based resources (pharmacies, hospital/clinic, medical supply, and home health company or health department) whereas modified low-protein foods indeed were often obtained from external sources (Internet and manufacturer). The relation of cost of product and source of product was not ascertained by the survey and should be the subject of further investigation.

\section{Conclusion}

As a society, we have accepted the utility of diagnosis and management of IMDs by initiating NBS programs. The rationale for NBS for IMDs is based on overwhelming evidence showing that initiation of prompt and effective therapies offers children with these metabolic conditions improved outcomes. For IMDs requiring special foods or formulas, dietary therapy is the primary effective treatment. We found that insurance or other resources do not consistently cover costs of medical foods used to treat IMDs, potentially resulting in inequities in access to these essential products. Greater awareness by health-care providers and policy makers of the challenges due to the lack of uniform coverage might help to close these gaps.

\section{ACKNOWLEDGMENTS}

The project was supported through a Cooperative Agreement between the Maternal and Child Health Bureau (MCHB), Genetic Services Branch, and the University of Texas Health Science Center at San Antonio, National Newborn Screening and Genetics Resource Center, Health Resources and Services Administration (HRSA) grant no. U32MC00148 and by HRSA-MCHB Regional Genetic and Newborn Screening Services Collaboratives, Heritable Disorders Program: Region 2 New York-Mid-Atlantic Consortium for Genetic and Newborn Screening Services, Cooperative Agreement No. U22MC03956; Region 3 Southeast Newborn Screening and Genetics Collaborative, Cooperative Agreement No. U22MC10979; and Region 4 Midwest Genetics Collaborative, Cooperative Agreement No. U22MC03963. The authors thank the investigators at the following institutions: University of Minnesota Amplatz Children's Hospital (Kristi Bentler); Cincinnati Children's Hospital Medical Center (Nancy Leslie); Emory University (Mary Brauchla); Greenwood Genetics Center (Melinda Whetsell and Neena Champaigne); University of Florida (Helen McCune and
Robert Zori); University of North Carolina-Chapel Hill (Dianne Frazier); University of Tennessee (Darla Henderson Smith); Vanderbilt University Medical Center (Gina Wey); Mount Sinai Medical Center (Roberta Salveson); Children's Hospital at Albany Medical Center (Katherine Marra); Children's Hospital of Pittsburgh (Judith Henry); Golisano Children's Hospital at Strong (Eileen Blakely); Maria Fareri Children's Hospital at Westchester Medical Center (Shideh Mofidi); University of Maryland Hospital for Children (Megan Skinner).

\section{DISCLOSURE}

The authors declare no conflict of interest. The views expressed in this publication are solely the opinions of the authors and do not necessarily reflect the official policies of the United States Department of Health and Human Services, the Health Resources and Services Administration, National Institutes of Health, or Centers for Disease Control and Prevention, nor does mention of the department or agency names imply endorsement by the US government.

\section{REFERENCES}

1. FDA. Guidance for industry: frequently asked questions about medical foods. US Department of Health and Human Services Food and Drug Administration Center for Food Safety and Applied Nutrition May 1997; Revised May 2007; <http://www.fda.gov/Food/GuidanceRegulation/ GuidanceDocumentsRegulatoryInformation/MedicalFoods/ucm054048.htm>. Accessed 25 April 2011.

2. MSDH. Mississippi WIC products. 2010; 28 September 2010 Updated 1 October 2010: http://www.healthyms.com/msdhsite/index. cfm/41,3983,128,508,pdf/WICFoods\%2Epdf. Accessed 25 April 2011.

3. Nutricia. My Special Diet Online Store. Myspecialdiet.com. www.myspecialdiet. com/shop/. Accessed 25 April 2011.

4. Camp KM, Lloyd-Puryear MA, Huntington KL. Nutritional treatment for inborn errors of metabolism: indications, regulations, and availability of medical foods and dietary supplements using phenylketonuria as an example. Mol Genet Metab 2012;107:3-9.

5. Insurance coverage of medically necessary foods and formula to treat disorders identified through newborn screening. National Council of State Legislatures 2008, http://www.ncsl.org/default.aspx?tabid=13865. Accessed 19 December 2011

6. Huntington K, Buist NR. Medical food treatment of inborn errors of metabolism and state legislative mandates. Top Clin Nutr 2009;24:289-306.

7. Weaver MA, Johnson A, Singh RH, Wilcox WR, Lloyd-Puryear MA, Watson MS Medical foods: inborn errors of metabolism and the reimbursement dilemma. Genet Med 2010;12:364-369.

8. Kaiser-Family-Foundation. statehealthfacts.org: Your source for state health data - Health Insurance Coverage of Children 0-18, states (20092010), US (2010). 2011, http://www.statehealthfacts.org/comparebar. jsp?ind $=127 \&$ cat $=3$. Accessed 5 January 2012 .

(1) $\odot$ This work is licensed under a Creative Commons Attribution-NonCommercial-No Derivative Works 3.0 License. To view a copy of this license, visit http://creativecommons.org/licenses/by-nc-nd/3.0/ 